\title{
Encontré un fósil y no supe qué hacer con él
}

\begin{abstract}
Al hacer una revisión del estado legal y social en el que se encuentra el Patrimonio Paleontológico de la Comunidad Autónoma de Andalucía me encuentro con una protección legal que no está desarrollada , un vacío técnico entre las filas de gestores de la Administración, un grupo de coleccionistas y comerciantes de fósiles que reciben cada año el permiso y un local del Ayuntamiento para venderlos, pequeñas colecciones mantenidas por diversos órganos de la misma administración que se ignoran y un pequeño grupo de paleontólogos que no disponen de recursos suficientes para atender la investigación, la creación de nuevas generaciones de paleontólogos y para prestarse al asesoramiento o a la gestión que requieren los continuos hallazgos de fósiles en nuestra rica región. Un panorama tan caótico como halagüeño para crear un gran debate sobre el patrimonio paleontológico entre los gestores, los investigadores y el resto de la sociedad.
\end{abstract}

Eloísa Bernáldez Sánchez

Laboratorio de Paleobiología del IAPH

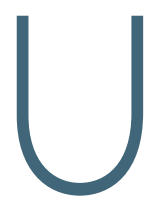

n sábado de Mayo de 1982: un grupo de tres amigos nos vamos a ver fósiles a Burguillos en la Sierra Norte de Sevilla donde el farmacéutico nos informa que encontró un cuerno de rinoceronte. Una vez allí encontré algunos fósiles terciarios marinos, nada de mamíferos terrestres, los únicos restos de mamíferos que vi fueron tres vértebras de un cetáceo, una ballena, en el cementerio del pueblo. Las recogí ante la estupefacción de los allí presentes y me las llevé a mi casa. El lunes siguiente llamé a la Consejería de Educación y Ciencia para informarme sobre el organismo que atiende este tipo de hallazgo, me enviaron al Museo Arqueológico de Sevilla donde me encuentro con una pila de cajas con fósiles, donados por otros aficionados, con los que no saben qué hacer.

Hoy, un día de Julio de 1998: a pesar de ejercer como paleobióloga en la Consejería de Cultura aún sigo sin saber qué hacer con las tres vértebras que continúan estando en mi casa y pienso si no debí dejarlas en el cementerio de Burguillos, donde eran más útiles como maceteros.

Esta parte de mi diario de campo no es anecdótico ni el título de este trabajo es una simple frase. Es un hecho que Andalucía presenta una gran riqueza paleobiológica, desconocida prácticamente por la administración, que no sabemos ni cómo valorarla ni dónde conservarla; es una riqueza incalculada hasta ahora e infravalorada con y sin leyes de protección porque, probablemente, a quienes más interesa este tema seamos unos pocos investigadores con grandes dificultades para afrontar la responsabilidad de nuestras propias líneas de investigación y la labor de gestores del patrimonio paleontológico. Una labor que debe asumir la Administración, no bajo el Reglamento de Actividades Arqueológicas, con la individualidad con la que otros apartados del patrimonio histórico lo han hecho y no porque cuatro investigadores le roguemos que atiendan nuestras demandas respecto al patrimonio paleontológico, sino porque la sociedad nos adelanta como siempre de manera caótica comercializando y destruyendo unos pocos lo que es de todos.

Quizás este sea el momento de abordar en línea recta el definitivo reconocimiento científico-social-económico del patrimonio paleontológico, ya que éste goza de reconocimiento legal en el ámbito nacional y regional a través de dos leyes nacionales, la Ley de Patrimonio Histórico Español ( $6 /$ / 985, 25 de Junio) y la Ley de Conservación de los Espacios Naturales y de la Flora y la Fauna Silvestres (4/1989, 27 de Marzo; art. 16.2); y otras autonómicas, la Ley del Patrimonio Histórico de Andalucía ( I / 1991, de 3 de julio) y Ley de Inventario de Espacios Naturales (art. I2). Sin mencionar las continuas alusiones a la protección de los fósiles en los Planes de Ordenación de los Recursos Naturales, en los Planes Rectores de Uso y Gestión de los Parques Naturales, en la Ley de Ordenación del Territorio de la Comunidad Autónoma de Andalucía y en el Texto Refundido de la Ley sobre Régimen del Suelo y Ordenación Urbana. Aún hemos encontrado mención al patrimonio cultural, donde se acoje el paleontológico, en el Plan DIA de la Consejería de Turismo y Deporte (ver listado legislativo).

Abruma la cantidad de leyes que contemplan la protección directa o indirecta de los fósiles y observar tan poca eficacia, tanta que ni siquiera está definido el patrimonio paleontológico, cuanto menos protegido, estudiado y difundido. Es tal la indiferencia que en el Foro de Debate del Plan General de Bienes Culturales de Andalucía 1996-2000 menciona la palabra paleontológico una sola vez en el apartado de la Mesa de Formación sin definición ni desarrollo de este concep- 
to. Luego, si existe la protección legal del patrimonio paleontológico, cómo podemos justificar la ignorancia y el caos en los que se mueve: no hay una normativa propia, no hay especialistas en la administración y, por el contrario, hay un fuerte movimiento social respecto de los fósiles que son exhibidos, coleccionados y vendidos, por contar entre las actividades más negativas, y un fuerte interés por el conocimiento del pasado como el factor más positivo.

\section{La actividad paleontológica desarrollada por la Junta de Andalucía}

Puedo asegurar que durante los últimos quince años han sido numerosos los avisos de hallazgos de fósiles y de lugares que merecen ser reconocidos por su gran interés paleontológico que deben ser protegidos, estudiados y divulgados para conocimiento de tantas personas que muestran cada día su interés y preocupación por el tema; no son científicos ni gestores, sólo gente con curiosidad que justifican que debemos ponernos en marcha. Hasta ahora la mayoría de las publicaciones (ver referencias bibliográficas) exponen los conflictos sobre este patrimonio desde el punto de vista del investigador que ve cómo se pierde algo irrecuperable del pasado, algunos hasta proponen cómo valorizarlo socialmente proporcionando a la administración ideas como las de realizar parques paleontológicos (Morales y Azanza, 1992) o sensibilizar y formar desde la escuela a través de los programas de educación ambiental; en este documento trato de añadir a todo ese trabajo que otros llevan años desempeñando el punto de vista de los no entendidos que quieren saber más. Esto significa que debemos tener un conocimiento del objeto a proteger que como bien apunta Morales y Alcalá (1994a, b; 1996) el patrimonio paleontológico aún hay que definirlo primero para valorarlo y luego tomar las medidas oportunas sobre su protección y estudio bajo unos criterios científicos, socio-económicos y culturales que respondan a las necesidades de la mayoría.

Siendo así, hemos de confeccionar un reglamento de actuación que, por parecido que tenga con el patrimonio arqueológico bajo cuya custodia se encuentra el primero, necesita sus propias reglas; algo que pueden avalar los arqueólogos que tienen bajo su responsabilidad un patrimonio que no entienden. Este es un trabajo que se viene haciendo en otros organismos. En estos días he consultado las normas de actuación de los Planes Rectores de Uso y Gestión de los Parques Naturales de Andalucía, su redacción es casi clónica, pero de esta manera consiguen recoger lo común de todo lo que es naturaleza y cultura matizando en las particularidades de un paisaje y otro. Algo así proponemos en la creación de un reglamento paleontológico: repetir todo lo que de común tengan ambos patrimonios que ahora comparten reglamento, añadiendo y restando todo lo que no sea operativo para el patrimonio paleontológico.

Haciendo un análisis sobre la experiencia oficial en estos años de la Junta de Andalucía en materia de Paleontología he observado que desde 1983, año en que se le concede al Dr. J. Gibert-Clols permiso para la excava- ción del yacimiento de Venta-Micena en Orce, hasta 1989 la actividad fue discretamente creciente, creo que se autorizó y se financió cada solicitud que los nueve o diez paleontólogos pedimos; después de esta fecha la actividad ha sido decreciente hasta llegar a ser nula en estos últimos años. Comenzamos en estos años con dos tipos de actividades: la confección de la Carta Paleontológica por parte de Sevilla, Cádiz y más tarde de Huelva y las excavaciones de yacimientos paleontológicos de forma rigurosa. Me consta que esas cartas han sido usadas por los gestores, pero nunca se ha fomentado su continuidad bajo un proyecto regional que reclute paleontólogos y geólogos en la realización de la Cartografía Paleontológica de Andalucía procedentes de las Universidades de Granada y Huelva entre otras instituciones; y hago hincapié en la participación de otros especialistas, además de los paleontólogos, porque el fósil contiene una doble naturaleza cultural y natural que implica un conocimiento profundo de la geología del sitio.

En una encuesta realizada por el IAPH entre las instituciones responsables del patrimonio paleontológico en nuestro país se ha comprobado que el desconocimiento y la inactividad en este terreno no es patrimonio andaluz, es general y en algunas comunidades están en peor situación. Tan sólo en Aragón existe un paleontólogo que gestiona este patrimonio desde hace cinco años y están confeccionando un reglamento al respecto (Royo y otros, 1997); el resto de los gobiernos tienen convenios con las universidades o con museos de Ciencias Naturales como el caso de Madrid, quizás la comunidad que más ha conseguido avanzar con su proyecto Cartografia Paleontológica de la Comunidad de Madrid, con ellos esta administración ha llegado a "normalizar" la actividad paleontológica en cuanto a conocimiento, protección y lugar de conservación a través de los científicos que se responsabilizan no sólo de su investigación, que puede ser o no rentable para la sociedad a corto plazo (la investigación siempre es rentable), sino también de su gestión sin entrar en conflictos de intereses.

Hasta 1992 había un buen movimiento e interés de la administración por escuchar y hasta por financiar esta actividad que en la actualidad es casi nula, debido posiblemente a razones financieras que suelen ser más nefastas sobre las actividades que gozan de menor reconocimiento. Pues bien, si como parece existe cierta empatía por parte de los gestores arqueólogos hacia el patrimonio paleontológico aprovechemos este receso negativo en la expansión de la investigación paleontológica, y en general para la ciencia de este país, para trazar planes de intervención en los próximos años. Recuerdo los primeros años de colaboración con la Consejería de Cultura en los que desbordaba la cantidad de yacimientos que había que excavar y estudiar, ahora que no tenemos tantos medios podemos estudiar el terreno como el que prepara el campo para la próxima cosecha. De esta manera nos ahorraremos desagradables sorpresas sobre los criterios y las medidas que debemos adoptar a la hora de enfocar un proyecto o de aprobarlo, porque aún cuando no sea la panacea servirá para que sepamos qué tenemos y cómo lo vamos a utilizar cuando nos encontremos ante un fósil o aún más cuando encontremos un magnífico yacimiento como el de Orce. 
Necesitamos un reglamento paleontológico entendido y llevado por uno o varios paleontólogos, hasta ese momento en el que la administración pueda contar entre sus filas con un paleontólogo-gestor puede trabajar con los expertos que considere, y tienen razón cuando en ese cuestionario enviado a la 17 comunidades autónomas nos contestan casi todos que apenas si tienen avisos o solicitudes para excavar yacimientos paleontológicos y es que somos insuficientes los investigadores abordando la dualidad de la Paleontología como ciencia y como fuente de patrimonio histórico y natural. Desde aquí hemos de reconocer la falta de presión científica por parte de paleobiólogos/paleontólogos que potencien esta especialidad dentro de las universidades andaluzas, única cantera que puede surtir de gestores y de asesores científicos a la Administración. Como esta labor requiere años para ser efectiva propongo que, con los medios actuales, comencemos a intervenir en la valoración, prevención, protección y difusión de la otra naturaleza muerta que no por muerta está desaparecida.

\section{La actividad paleontológica desarrollada por la sociedad}

Si todas las razones argumentadas anteriormente no fuesen suficientes para arrancar, aún puedo añadir que hay una realidad que habrá que solucionar en poco tiempo: la propia sociedad está tomando desde hace muchos años sus propias salidas a este desconcierto creando pequeños museos y colecciones privadas que se están fomentado fuera y dentro de Andalucía. Cuando algún instituto de enseñanza media o un ayuntamiento recoge, protege y exhibe este material, al mismo tiempo que está afortunadamente mimando el patrimonio histórico está incumpliendo la ley que debe administrar y conocer la Consejería de Cultura.

Es asombroso el número de colecciones que ha recogido Oñate (|99|) en su I Catálogo General de Colecciones Históricas y Científicas de Ciencias Naturales de Andalucía donde he estimado que más del $90 \%$ de las colecciones de corte biológico contienen fósiles apenas descritos y valorados, algunos de colecciones del siglo pasado (la edición de este libro está financiada por dos Consejerías, Educación y Ciencia y la de Medio Ambiente) incluyendo a un grupo de aficionados a la mineralogía que exponen y venden los fósiles en un local del Ayuntamiento de Sevilla desde hace 19 años, tanta es su confianza que al entrar en el reciento te invitan a inscribirte en su asociación. Piensen en una asociación de aficionados a la arqueología vendiendo monedas y ajuares romanos, fenicios o de cualquier otra cultura, o vendiendo árboles de algún parque natural ¿es legal? Y no es una pregunta sarcástica, es solo una pregunta para que alguien me responda. De todas formas está claro que necesitamos ampliar los apartados que enumeran los proyectos de educación ambiental porque quién vende objetos arqueológicos o artísticos sabe que inflige la ley y toma medidas clandestinas; pero los que venden objetos paleontológicos no deben tener esa conciencia cuando hasta se anuncian y se les conceden locales municipales.
Estas actuaciones de la sociedad aparentemente negativas son para mí los más positivo que le ha ocurrido a esa parte del patrimonio paleontológico que no ha sido demolido en las explotaciones del suelo, de las que tan sólo en una ocasión se demandó el informe paleontológico de un terreno destinado para gravera en las terrazas del Guadalquivir. Sin embargo, sólo hay que consultar el registro de explotaciones mineras o darse un paseo por estos lugares para medir la asiduidad de este tipo de peticiones y actuaciones. Como un ejemplo de la falta de criterio y conocimiento paleontológicos pongo a estas mismas graveras donde se está perdiendo un importante patrimonio cultural y natural, se están demoliendo piezas óseas de elefantes conectadas a niveles del Musteriense de las que tuve conocimiento a través del infatigable Sr. Francisco Sousa que las ha recogido, custodiado, restaurado e investigado durante años, hasta conseguir un museo en la localidad de San José de la Rinconada financiado por la Diputación Provincial de Sevilla. Conseguido el rescate, la conservación y exhibición de estos magníficos fósiles es imposible reprochar la labor realizada aunque no sea la Consejería de Cultura quién haya intervenido, espero que, al menos, conozca su existencia. Este desconcierto debemos contrarrestarlo aunando el conocimiento de cuantos organismos y personas están interesadas o les competen la protección de los fósiles.

\section{Los basureros históricos en el patrimonio paleontológico}

En Bernáldez (1998) justifiqué la razón para proponer que cualquier material paleoorgánico procedente de las excavaciones arqueológicas es material fósil o subfósil al que se le debe la misma consideración científica y administrativa que el resto de lo hallado en el yacimiento, que en potencia puede formar parte del patrimonio paleontológico. En las 50 excavaciones arqueológicas en las que he participado hallé restos orgánicos $y$, sin embargo, no más del $6 \%$ realizan estudios paleobiológicos; de modo que estamos despreciando uno de los hechos más característicos del ser viviente al que solemos resumirlo en esa frase de que el hombre es lo que come a la que añadiría y lo que tira. Pues lo que tira está recogido en los basureros prehistóricos e históricos, así que estamos tirando historia.

La propuesta de incorporar el material paleoorgánico procedente de las excavaciones arqueológicas a las filas del patrimonio paleontológico salvaguardaría los grandes basureros históricos situados en los exteriores de las antiguas murallas de nuestras ciudades. En el caso de Sevilla encontramos grandes basureros desde época islámica a las puertas de esas murallas, sirviéndonos para delimitar esas estructuras y para entender la dinámica urbanística desarrollada durante siglos; por ello he propuesto que en las Cartas de Riesgo de las Ciudades Históricas se contemple con la máxima importancia las remociones de suelo en la zona extramuro de la ciudad, caso de la calle Florida o de la calle Torneo. Disponemos de una documentación de la época que nos lleva a definir la zona de riesgo en la que cambiaremos las medidas de protec- 
ción por las de estudio y difusión. Quizás sea excesivo pedir que los basureros históricos se declaren Monumentos Naturales y/o BIC, pero, al menos, debemos estudiar el contenido económico y ecológico que durante siglos ha permanecido casi intacto.

\section{Comencemos a actuar}

La propuesta que se hace desde aquí es comenzar a calibrar el valor paleontológico de nuestra región encomendando la confección de la Cartografía Paleontológica de Andalucía a un grupo de investigadores coordinado por un gestor-paleontólogo de la Consejería de Cultura. Realizar este trabajo es lento y arduo por lo que conviene marcarnos metas a corto plazo, para ello propongo que colaboremos con la Consejería de Medio Ambiente cuyos informes de Impacto Ambiental requieren informes sobre el patrimonio histórico en los que deberemos incluir los paleontológicos. Por otra parte, porponemos a la Consejería de Medio Ambiente que autorice la elaboración de las Cartas Paleontológicas de los Parques Naturales, con ello conseguiremos revalorizar el Parque aumentando los co- nocimientos naturales y culturales, al mismo tiempo que contaríamos con la colaboración de su propia guardería. Este último hecho podría solucionar en parte el problema de la vigilancia de las zonas que la requieran.

El desarrollo de estas actividades necesita que entremos en contacto todos aquéllos que nos interesa la cultura y la naturaleza. Hay una propuesta de la Sociedad Española de Paleontología, desde la Comisión del Patrimonio Paleontológico, para que sea Andalucía un lugar de encuentro de expertos y gestores. El IAPH ha propuesto que debemos reunirnos los investigadores que vienen participando en la gestión del patrimonio paleontológico como asesores, los arqueólogos que vienen siendo los verdaderos gestores (han respondido unánimemente a participar en esa reunión) y algunos representantes de otras instituciones implicadas en la conservación o destrucción de ese patrimonio como son las Consejerías de Medio Ambiente y de Obras Públicas, diputaciones y ayuntamientos; si esta vez no lo conseguimos... iremos por la siguiente.

\section{Anexo}

La legalidad del patrimonio paleontológico

I. Ley 16/1985, de 25 de junio, del Patrimonio Histórico Español.

2. Ley I/I99I, de 3 de julio, del Patrimonio Histórico de Andalucía.

3. Plan General de Bienes Culturales.

4. Decreto 4/1993, de 26 de enero, del Reglamento de Actividades Arqueológicas.

5. Decreto 19/1995, de 7 de febrero, del Reglamento de Protección y Fomento del patrimonio Histórico.

6. Decreto 106/1995, de 15 de abril, sobre el Plan de Bienes Culturales de Andalucía para 1996-2000.

7. Ley 2/1984, de 9 de enero, para el Sistema Andaluz de Museos.

8. Ley 4/1989, de 27 de marzo, de la Conservación de Espacios Naturales, de la Fauna y de la Flora Silvestres de Andalucía.
8. I. Planes de Ordenación de los Recursos Naturales.

8.2. Planes Rectores de Uso y Gestión de los Parques Naturales.

9. Ley 2/1989, de 18 de julio, de Inventario de espacios Naturales de Andalucía.

10. Real Decreto Legislativo 1302//986. Reglamento para el Estudio de Impacto Ambiental.

I I. Ley de Ordenación del Territorio de la Comunidad Autónoma de Andalucía.

I I. I. Planes de Ordenación del Territorio de Ámbito Subregional.

1 1.2. Programa Regional de Planeamiento en Centros Históricos. Orden de 9 de mayo de 1994 de las Consejerías de Obras Públicas y transporte, de Cultura y de Medio Ambiente.

I 1.3. Texto Refundido de la Ley sobre Régimen del Suelo y Ordenación Urbana.

\section{Referencias bibliográficas}

I. ALCALÁ, L. \& J. MORALES. 1994. Towards a definition of the Spanish palaeontological heritage. En: Geological and Landscape Conservation. D. O'Halloran, C. Green, M. Harley, M. Stanley \& J. Knill (eds). Geological Society: 57-6I.

2. ALCALÁ, L. \& J. MORALES. 1994. The palaeontological heritage of the Community of Madrid. Mém. Soc. Géol. Fr., 165: 13-15.

3. ALCALÁ, L. \& J. MORALES. 1996. The fossil mammal collection of the Museo Nacional de Ciencias Naturales, Madrid, as a research tool. Second World Congress on the Preservation and Conservation of Natural History Collections. 20th-24th August 1996. University of Cambridge.

4. ARAGONÉS, E.; A. ABAD, J. AGUSTÍ, J. GÓMEZ-ALBA i C. LÓPEZ. 1991. Documentació i instruccions per a la formació de col-leccions paleontològiques. Paleontologia. Generalitat de Catalunya. Departament de Cultura.

5. BERNÁLDEZ, E y M. BERNÁLDEZ. 1998. El criterio paleobiológico en la conservación de las ciudades históricas. Congreso Ciudades Históricas Vivas. Ciudades del pasado: pervivencia y desarrollo. Mérida, 30,3I de Enero y I de Febrero de 1997.
6. COLÓN DÍAZ, M. 1989. La protección del legado cuaternario: medios naturales y paisajes culturales. El Cuaternario en Andalucía Occidental. AEQUA Monografías, I: 189-193.

7. GRUBE,A.T.. 1991. Earth science conservation in Germany. An outline. $1^{\circ}$ Symposium International sur la protection du patrimoine géologique. Digne, France, II - 16 Juin 1991.

8. MELÉNDEZ, G. y M. SORIA. 1997. Problemática actual de la legislación sobre el patrimonio paleontológico en España. Medidas y soluciones. Zubía, 15: I | 3- 120.

9. MORALES, J. y B. AZANZA. 1992. Los parques paleontológicos, una alternativa de gestión para recursos paleontológicos de alto potencial didáctico, cultural y turístico. II Reunión Nacional de la Comisión de Patrimonio Geológico: 5 1-54.

10. OÑATE, F.J. 1991. I Catálogo Genral de Colecciones Históricas y Científicas de Ciencias naturales de Andalucía. Sevilla.

I I. ROYO GUILLÉN, J.I. 1997. "La gestión de la arqueología y la paleontología en Aragón: 10 años de competencias (1985-1995)". Arqueología Aragonesa, 1994: 465-478. 